\title{
ИСТОРИЧЕСКАЯ МОДЕЛЬ ИССЛЕДОВАНИЙ КАЧЕСТВА ЖИЗНИ НАСЕЛЕНИЯ
}

\author{
(ㄷ) 2021 Рыжова Ася Сергеевна \\ ассистент кафедры управления человеческими ресурсами \\ Института управления, экономики и финансов \\ Казанский (Приволжский) федеральный университет, Россия, Казань \\ E-mail: a.s.ryzhova@yandex.ru
}

В работе представлена эволюция исследований качества жизни населения. Проанализированы существующие представления о качестве жизни населения, выявлены их достоинства и недостатки, представлена авторская трактовка.

Ключевые слова: качество жизни населения, уровень жизни населения, благосостояние, человеческий капитал

В течение последних десятилетий важность проблемы качества жизни непрерывно возрастает. Этой сфере уделяется внимание на государственном уровне. По мнению Президента РФ Путина В.В. «Развитие человека - это основная цель и необходимое условие прогресса современного общества. Это и сегодня, и в долгосрочной перспективе наш абсолютный национальный приоритет. Ведь переход на инновационный путь развития страны связан с масштабными инвестициями в человеческий капитал» [1].

Качество жизни выступает всеобъемлющим понятием, затрагивает различные сферы жизни общества. Изменение качества жизни отражается на экономическом росте страны, влияет на развитие культуры, формирует социальный уклад, образ жизни населения и тесно связано с ростом качества человеческого капитала. Мы считаем, что проблема роста качества жизни была в той или иной мере актуальна на протяжении всей истории человечества.

Мы согласны с мнением Щеткина А.В. [23], что античная философия послужила основой для формирования теоретических предпосылок исследования качества жизни, а также заложила фундамент для социально-философского подхода к изучению качества жизни [23]. Такие мыслители, как Платон, Сократ, Аристотель, Лукреций, Эпикур приравнивали высокое качество жизни к моральному совершенству человека, его духовной свободе. По мнению одного из античных философов, достичь высокого качества жизни можно путем развития добродетелей и просвещения, а также путем проживания жизни в соответствии с писаными и неписаными законами идеального государства [15].
Средневековая философия также затрагивала проблемы, сопоставимые с современным исследованием качества жизни. Например, Фома Аквинский и Августин рассматривали любовь к Богу как единственный путь к улучшению жизни. Благополучие рассматривалось не как увеличение собственного богатства и служение государству, а как полное подчинение Божественной воле [23].

В философии Нового времени идея качества жизни была затронута в теории общественного договора. Сторонники данной теории (Дж. Локк, Ж.-Ж. Руссо, Ш. Монтескье и Т. Гоббс) говорили об общественном договоре как об акте перехода людей из естественного в гражданское состояние. Т. Гоббс считал, что в этом случае перед человеком открывается больше возможностей для удовлетворения своих потребностей, то есть его качество жизни улучшается [6].

Философия эпохи Просвещения также внесла свой вклад в формирование основ понятия качества жизни. Например, Г.А. Гельвеций [5] отождествлял высокое качество жизни с состоянием счастья, а достижение его возможно только при помощи государства. «Единственное средство - привлечь внимание широкой публики к проблеме идеального законодательства - это упростить проблему и свети ее к двум следующим положениям. Первая задача заключается в том, чтобы открыть законы, способные делать людей максимально счастливыми... Вторая задача - открыть средства, при помощи которых можно незаметно перевести народ из состояния несчастья, в котором он находится, в состояние счастья, которым можно наслаждаться» [5, с. 427].

И. Кант, как представитель немецкой классической философии, также затрагивал вопросы, 
в той или иной мере явившиеся предпосылкой к формированию понятия качества жизни. Философ писал о том, что достижение благополучия (высокого качества жизни) возможно лишь при сформированном гражданско-правовом обществе, которое было бы способно ограничить людей от негативного влияния других его членов и обеспечить гражданам защиту [23].

Философия марксизма-ленинизма привнесла свой вклад в понятие качества жизни. С ее развитием все больше укреплялась идея о том, что качество человека сильно взаимосвязано со строем того общества, в котором он живет. Представители данной философии (В.И. Ленин, К. Маркс, Ф. Энгельс) рассматривали общественное устройство, сложившееся во многих странах, как источник формирования всех отрицательных качеств людей. Например, по мнению К. Маркса и Ф. Энгельса, вследствие установления капиталистического строя, человек перестал быть существом добрым, «неотчужденным», целостным. Для исправления ситуации они настаивали на изменении общественного строя с целью формирования нового, основанного на равенстве, справедливости и гуманизме. По мнению философов данного направления, достойное качество жизни возможно иметь лишь в коммунистическом обществе [12, с. 350].

Мы разделяем мнение Щеткина А.В., что русская философия также оказала свое влияние на развитие понятия качества жизни. В отличие от представлений зарубежных философов, в России значительную роль в понимании вопросов, касающихся качества жизни, играла духовная составляющая [23]. Такие представители русской философии, как И.В. Кириевский, Н.А. Бердяев, Л.Н. Толстой, В.С. Соловьев уделяли большое внимание нравственности, религиозности в рассмотрении проблем, касающихся качества жизни. Например, Л.Н. Толстой писал о том, что для благополучия человек должен «опроститься», то есть вести более скромный образ жизни, отказаться от всяческого принуждения и насилия [Цит. по 23]. И.А. Ильин, как один из представителей русской философии, более комплексно рассматривал проблему качества жизни, придавал большое значение качеству различных сторон жизни общества: культуры, хозяйства, образования, профессиональной деятельности, политики, воспитания [9].

Несмотря на то, что рассмотренные выше взгляды различных философов на вопросы, ка- сающиеся качества жизни, были довольно разнообразны, само понятие сформировалось намного позже. Его предшественником служил термин «уровень жизни».

Во второй половине XX века понятие «уровень жизни» перестало в полной мере отражать условия жизни развитых стран. С возникновением последствий научно-технического прогресса (ухудшение экологической ситуации, рост безработицы, экономические кризисы и другие процессы и явления, оказывающие сильное влияние на жизнь людей) возникла необходимость в более комплексном понятии, которое отражало бы все условия жизни человека и степень удовлетворения различных категорий его потребностей и интересов.

Понятие «качество жизни» как категория экономической науки впервые появляется в конце 1950-х гг. в работе Дж. Гэлбрейта «Общество изобилия» [7], считавшего, что в обществе, где у людей не удовлетворены их первичные потребности (пища, комфорт, здоровье), увеличение доходов является важнейшей целью экономики. Само качество жизни Дж. Гэлбрейт понимал как все блага, которыми может пользоваться человек в «развитом индустриальном обществе», «обществе менеджеров» [14]. Позднее данный термин был упомянут социологом Д. Рисменом в его работе «Одинокая толпа». В этот же период начинается процесс формирования стандартов качества товаров, услуг, экологии окружающей среды, утверждаются стандарты здорового образа жизни, образования, одежды, пищи.

В политическом лексиконе понятие «качество жизни» появилось в 1963 году в «Докладе о положении нации» президента США Дж. Кеннеди. Глава США утверждал, что «качество американской жизни должно идти в ногу с количеством американских товаров». Также термин «качество жизни» был использован в 1964 г. президентом Л. Джонсон, выдвинувшим следующий тезис: «цели американского общества не могут быть измерены размером наших банковских депозитов. Они могут быть измерены качеством жизни наших людей» [23].

Таким образом, зарождение концепции качества жизни началось в 1950-х - 1960-х гг. прошлого столетия. В данный период времени качество жизни рассматривается с точки зрения американского общества, его образа жизни, бытовых и культурных стандартов США [21]. Одна- 
ко все еще понятие качества жизни не было четко разграничено с понятиями образа и уровня жизни, качество жизни отождествлялось со стилем жизни, определенным уровнем стандартов.

Следующая стадия развития концепции качества жизни, «квантификационная» получила свое начало с выходом в свет в 1966 г. монографии «Социальные индикаторы» под редакцией Р. Бауэра. Данный труд явился основой отдельному направлению социологии. Теперь качество жизни рассматривается как «социальное благоденствие» и описывается через «обеспеченность, свободу, справедливость, вежливость, любезность и спокойствие» [27, с. 34]. В это же время предпринимаются первые попытки оценить качество жизни. Оно рассматривается как набор экономических, социальных, физических, политических и прочих факторов, влияющих на жизнь человека. Качество жизни оценивается через значительное количество индикаторов [2].

В свою очередь, отечественная наука данного периода не признавала понятие «качество жизни», оно подвергалось активной критике. Причина этого связана с марксистским подходом, рассмотренным ранее. Западная наука не уделяла достаточного внимания значимости способа производства в формировании условий жизни людей, что не совпадало со взглядами отечественных ученых. Тем не менее, западная наука продолжала разработку концепции качества жизни, включающую в себя все сферы жизни человека, а не только материальный аспект [26, с. 12].

Качество жизни стало рассматриваться как категория будущего, как некий идеал, достичь который можно лишь при переходе общества на новую ступень развития - гармонию социальных и культурных ценностей. Большой вклад в развитие данной идеи внес американский социолог Э. Тоффлер и его труд «Футурошок»[25], где он рассматривает понятие качества жизни как совокупность экологического, экономического и социального аспектов.

Рассматривая экологический аспект, автор говорит о том, что человек и природа должны существовать в полной гармонии, а также считает, что высокого качества жизни можно достичь путем «борьбы против загрязнений, борьбы с увеличением плотности населения, шумом, то есть путем восстановления физической жизненной среды и улучшения того, что должно быть названо качеством жизни».

Говоря об экономическом аспекте, Э. Тоф- флер также делает акцент на уходе от концепции, основанной исключительно на материальных ценностях. По его мнению, высокое качество жизни может быть достигнуто при переходе от удовлетворения «основных материальных нужд потребителя» к удовлетворению «утонченных, видоизмененных личных потребностей потребителя в красоте, индивидуализации, престиже» [20, с. 94-95]. Э. Тоффлер включил психологический аспект в понятие качества жизни одним из первых.

Э. Тоффлер оппонировал Р. Бауэру и считал, что качество жизни невозможно измерить через «социальные индикаторы», так как данное понятие относится больше к социальной, а не к экономической сфере.

Таким образом, периоду конца 1960-х - начала 1970-х годов свойственно рассмотрение качества жизни как социального понятия. Качество жизни выступает понятием, включающим в себя как материальные, так и социальные, политические, экологические, нравственные и демографические условия жизни человека, которые не были включены в понятие «уровень жизни» [11, с. 3]. В данный период начинается формирование «технологии оценивания» качества жизни и зарождается методическая база его исследования.

Большое значение в развитии понятия «качество жизни» играл Римский клуб. К его представителям относились такие ученые, как Э. Пестель, Д. Медоуз, Д. Форрестер, М. Месаревич и др. За все время существования Римского клуба было сформировано примерно 20 моделей качества жизни. Члены клуба поддерживали идеи «нулевого» и «органического роста» [8].

Сафиуллин А.Р. считает, что теория «нулевого роста» предполагала с целью улучшения качества жизни остановить рост рождаемости, экономический рост, рост потребления, нанесение вреда экологии [19].

Позже на смену данной теории, по мнению Бестужева-Лада И.В., Батыгина Г. С, пришла теория «органического роста», предполагавшая компенсацию продолжения роста там, где это можно считать необходимым [2].

Римский клуб ставил перед собой следующую цель: «...установить тот уровень, на котором стремление к росту останется совместимым с размерами нашей небольшой планеты и с основными потребностями формирующегося мирового сообщества - от снижения социальной 
и политической напряженности до повышения качества жизни каждого человека. Необходимо определить и исследовать основные факторы, влияющие на долгосрочное поведение мировой системы, и их взаимодействие» [18, с. 71].

Мы считаем, что понятие качества жизни, предложенные Римским клубом, не были достаточно точны и однозначны. Представители данного направления делали акцент на «внешних» факторах, оказывающих влияние на человека. Качество жизни выступало способом измерения функционирования мировой системы. В этот период предпринимались попытки оценить качество жизни через материальный достаток, качество и достаточность пищи, степень загрязнения окружающей среды, плотность населения.

По мнению Д. Форрестера, расчет такого показателя, как «среднемировое значение качества жизни», может позволить сравнивать варианты развития человечества в зависимости от изменения влияния вышеуказанных факторов [3, с. 69]. Если первые трактовки качества жизни, предложенные Римским клубом, были довольно узкими, то впоследствии все больше внимания стало уделяться широкому кругу мировых проблем и аспектов качества жизни. Это было вызвано тем, что представители Римского клуба переместили свое внимание на цели экономического роста. Первый президент Римского клуба А. Печчеи писал о том, что экономический рост способен понизить качество жизни. Экономический рост должен, по его мнению, существовать только в том случае, если он служит гуманным целям [4]. Впоследствии на смену концепции экономического роста пришла «концепция социально-экономического прогресса, измеренного в терминах качества жизни». Данные изменения были вызваны обострившимися кризисными явлениями в социально-экономической жизни Запада в 1970-х годах. Такое положение развитых стран показало необходимость анализа взаимосвязи между экономическим ростом и качеством жизни человека.

В связи с этим в зарубежной науке формируются два течения - «неолиберальное» и «леворадикальное», отличающиеся своими взглядами на проблему достижения оптимального качества жизни. K «неолибералистам» относили себя 3. Бжезинский, Г. Канн, Д. Белл, А. Тоффлер, Р. Арон, Ж. Фурастье, У. Ростоу, Э. Вингер и др. Представителями второго течения являлись Э. Мишан, Ф. Розак, Дж. Макдеморт, Л. Мэмфорд,
Э. Фромм, Т. Аттали, Б. Скиннер и др.

По мнению представителя «неолиберального» течения У. Ростоу, высокое качество жизни является закономерной стадией развития общества потребления. Он считал, что повышение качества жизни неизбежно последует за экономическим ростом, основанном на научно-техническом прогрессе. У. Ростоу писал о том, что «новое качество жизни» определяется показателями в области загрязнения окружающей среды, здравоохранения, борьбы против социального неравенства и бедности, отдыха и др. [24, c. 99] Д. Белл и 3. Бжезинский считали, что «новое качество жизни» можно достичь путем использования результатов научно-технического прогресса, внедрения новых технологий, что приведет к снижению нагрузки на окружающую среду и позволит ограничить людей от опасных видов деятельности. По их мнению, качество жизни выступает элементом постиндустриального общества, которому свойственно увеличение времени отдыха, улучшение условий труда, рост доходов, доступ к медицине, образованию, культуре для большего количества людей [10].

Р. Арон, в свою очередь говорил о том, что технический прогресс должен находиться во власти человека с тем, чтобы его отрицательное влияние на окружающую среду не превышало его положительные эффекты.

Представители «леворадикального» направления, наоборот, придерживались мнения, что экономический рост и технический прогресс негативно влияют на качество жизни населения.

Например, английскому экономисту Э. Мишану принадлежит идея остановки экономического роста. По его мнению, это является условием защиты качества жизни от ухудшения. Э. Мишан писал, что качество жизни должно прежде всего иметь социальное содержание и, следовательно, должно отождествляться с «благоденствием или счастьем обыкновенных людей». В соответствии с взглядами Э. Мишана, понятие качество жизни пересекается с такими понятиями, как «свобода, вежливость, обеспеченность, справедливость, спокойствие, любезность» [10].

Л. Мэмфорд считал, что лучшее качество жизни было достигнуто людьми в прошлом, в частности, в средневековье. Ученый выступал за отмену специализации труда и регламентации жизни. По его мнению, это приведет к «интенсификации жизни», при которой власть 
и прибыль перестанут быть главными целями человека. Подобные взгляды разделял экономист Ф. Розак. [10] Он выступал за отказ от научного рационального мышления и переход к религиозному мышлению прошлого. Свою точку зрения ученые объясняли тем, что только возврат к прошлому способен нейтрализовать негативные последствия экономического роста. По их мнению, после возврата к прошлому человечество потеряет в количестве, но приобретет в качестве, проиграет материально, но выиграет духовно.

Во второй половине 1970-х годов происходит формирование концепции «ощущаемого (субъективного) качества жизни». Сильное влияние на данный процесс оказали американские экономисты и социологи Ф. Конверс, А. Кэмпбелл, Ф. Роджерс, Дж. Рабье, С. Уитни, Р. Инглехарт.

В трактовке Р. Инглехарта и Дж. Рабье качество жизни выступает как сумма степеней удовлетворенности людей разными аспектами жизни [28] А. Кэмпбелл делал акцент на «внутреннем самочувствии» человека [29]. В своих работах ученые подчеркивали необходимость оценки условий жизни людей. Качество жизни связывается с индивидуальным благополучием, отраженным в оценке человеком степени своего удовлетворения жизнью [1167].

В это время субъективный подход получает свою популярность также в Западной Европе, Японии, Канаде и Австралии. Концепция «ощущаемого качества жизни» формирует целую систему социальных показателей - «субъективных показателей качества жизни». Все более популярной в данный период становится идея того, что чисто экономический подход к решению проблемы измерения качества жизни очень ограничен, так как качество жизни в большей степени является социальной категорией [13].

В 1970-х годах развитие концепции качества жизни становится популярным среди отечественных ученых. Несмотря на то, что качество жизни в СССР того периода было невысоким относительно западных стран, теоретические исследования данного понятия все же проводились. Наибольший вклад в данный процесс внесли такие социологи и философы, как В. Толстых, И. Бестужев-Лада, С. Попов, А. Ревайкин и др. Большую известность приобрел труд С. Попова «Проблема качества жизни в современной идеологической борьбе», изданный в 1977 г. Ученый отождествлял понятие «качества жизни» c «уровнем жизни» и «образом жизни» [16].

В то же время публикуется реферативный сборник АН СССР «Качество жизни: концепция и практика», издаются многочисленные книги сотрудников Института социологических исследований АН СССР. Наиболее популярным в отечественной науке становится субъективистский подход. Это объясняется тем, что в советской науке понятие «качество жизни» сформировалось через исследование образа жизни. В результате чего отечественная наука стала придерживаться мнения, что «качество жизни» описывает только те аспекты общественной и личной жизни человека, которые не могут быть измерены количественно [21]. Большую популярность имела «марксистская» теория. Данный подход делал акцент на качественных характеристиках жизни человека. По словам К. Маркса, «...люди в первую очередь должны пить, есть, одеваться и иметь жилище, прежде чем заниматься наукой, политикой, религией, искусством и др.» [12, с. 350].

С.И.Попов [16], в свою очередь, рассматривал качество жизни, как одну из сторон образа жизни. По его мнению, образ жизни выступает «типичными, практикуемыми нормами поведения людей, способом их повседневной деятельности в сфере быта и труда, в потреблении материальных и духовных ценностей, а также в производстве». Образ жизни он разделял на два взаимосвязанных элемента: количественный и качественный, последний из которых и приравнивался к качеству жизни. С.И. Попов писал: «Если количественная сторона образа жизни фиксируется главным образом в определенной системе показателей материального благосостояния, сводится к уровню жизни, то качественная сторона образа жизни - это комплексная, интегральная характеристика положения человека в различных социальных системах, выражающая степень его социальной свободы, возможности всестороннего развития, совокупность культурных и духовных ценностей, предоставленных в его распоряжение»[16, с. 149-159].

В работе Фахрутдиновой Е.В. рассмотрена эволюция категории качество жизни населения. По ее мнению, множество различных подходов к определению качества жизни со стороны специалистов и научных организаций различных сфер деятельности, разнообразие оценок, отсутствие единства в наборе показателей и индикаторов послужили основой для систематизации подходов к определению сущности и иссле- 
дованию качества жизни. В процессе развития общества категория «качество жизни» менялась, уточнялась, обогащалась и развивалась [22, с. 67].

В современных реалиях развития информационного общества и всеобщей цифровизации категория качество жизни населения ускоренно эволюционирует и должна включать в себя новые элементы, такие как цифровая компетенция, обеспеченность населения цифровыми благами, доступность электронных цифровых услуг населению, в том числе и государственных, безопасность информационной деятельности населения.

\section{Библиографический список}

1. Абсолютным национальным приоритетом России являются инвестиции в человеческий капитал - Путин// Режим доступа https://www.trend.az/world/russia/1131104. html свободный (дата обращения 11.09.2021)

2. Бестужев-Лада И.В., Батыгин Г.С. О «Качестве жизни»// Режим доступа http://www.psihdocs.ru/pars_docs/re fs/103/102686/102686. pdf свободный (дата обращения 11.10.2021)

3. Бубер М. Проблема человека // Философские науки 1992, № 3, с. 65-82

4. Булгаков С.Н. Два града: исследование о природе общественных идеалов/Спб, Издательство Русского христианского гуманитарного института. 1997. - 589 с.

5. Гельвеций К.А. Сочинения в 2-х томах. М. 1974. Т. 2. С. 427

6. Гоббс Т, Избранные произведения в 2-х томах, т. 2.

7. Гэлбейт Дж. «Общество изобилия»// Современная экономическая мысль. - 2018. - 404c.

8. Елисеева И.И. Социальная статистика: Учебник./Под ред. И.И. Елисеевой. - М.: «Финансы и статистика», 2003. $-156 \mathrm{c}$.

9. Ильин И.А. Спасение в качестве// Антология русского качества/Сост.Б. В. Бойцов, Ю.В. Крянев и др. М., 2000, c. $10-14$

10. Жохов А.Н. Региональный аспект управления качеством жизни населения: дис. ... канд. экон. наук: 08.00 .05 Великий Новгород, 2006, 170 с., с. 107

11. Каракотова А.О. Социально-философский анализ качества жизни. Автореф. дис....канд. филос. наук. Ставрополь, 2002, 22 с.

12. Маркс К., Энгельс Ф. Соч. 2-ое изд. - М.: Политиздат, 1961. - Т. 19. - 670 с., с. 350

13. Мосякина Е. А. Оценка качества жизни населения в субъектах РФ, дисс. канд. экон. Наук, 2015.

14. Новая экономическая энциклопедия, 2-е изд. М.:ИНФРА-М 2006-VI, 810с.,

15. Платон. Сочинения в 3-х томах, Москва, 1971, т. 3 ч. 1.

16. Попов С. И. Буржуазная социология в поисках нового «качества жизни» // СОЦИС. - 1977. - № 1. - С. $149-159$.

17. Попов С.И. Проблема «качества жизни» в современной идеологической борьбе. - М. Политиздат, 1977. $280 \mathrm{c}$.

18. Пестель Э. За пределами роста, М. 1988, 155 с.

19. Сафиуллин А.Р. Экономика благосостояния. Теория и практика. Учебное пособие. - Ульяновск: Ульяновский государственный технический университет (УлГТУ), 2007. - 111 с.

20. Современные концепции уровня, качества и образа жизни. М. - 1978._115 с.

21. Тодоров А. С. Качество жизни. Критический анализ буржуазных концепций. Под ред. С.И. Попова. - М. Прогресс, 1980. - 224 с.

22. Фахрутдинова Е.В. Качество жизни населения в системе социально-экономических отношений (институциональный подход)// диссертация на соискание ученой степени доктора экономических наук/Казанский финансово-экономических институт. Казань, 2010. - 420с.

23. Щеткин А.В. Качество жизни в контексте философского знания // Вестник ОГУ. - 2007. - № 7. - С. $54-157$.

24. Эпплер Э. Альтернативы гуманного общества. Кельн, 1974// Социально-экономические аспекты концепции «качества жизни». Реферативный сборник. М. АН СССР ИНИОН, вып. 5, 1977, с. 99

25. Human development report 2007/2008. Fighting climate change: human solidatity in a divided world. United nation development program. - New York 2008, $399 \mathrm{p}$

26. Bloom, David E., Canning, David. The Health and Wealth of Nations // Science. - 2000. - Vol. 287. Issue 5456. - P. 1207-1209 